\title{
An Emergent Entity: Indolent Mucormycosis of the Paranasal Sinuses. A Multicenter Study
}

\author{
Erika Celis-Aguilar ${ }^{1}$ Alan Burgos-Páez ${ }^{1}$ Nadia Villanueva-Ramos ${ }^{1}$ José Solórzano-Barrón ${ }^{1}$ \\ Alma De La Mora-Fernández ${ }^{1}$ Juan Manjarrez-Velázquez ${ }^{2}$ Sergio Verdiales-Lugo ${ }^{1}$ \\ Lucero Escobar-Aispuro ${ }^{1}$ Perla Becerril ${ }^{3}$ Ana Valdez-Flores ${ }^{4}$ Francisco Javier Merino-Ramírez ${ }^{4}$ \\ Carmen Beatriz Caballero-Rodríguez ${ }^{4}$ \\ ${ }^{1}$ Department of Otolaryngology, Centro de Investigación y Docencia \\ en Ciencias de la Salud (CIDOCS) de la Universidad Autónoma de \\ Sinaloa, Culiacán, Sinaloa, México \\ 2 Department of Otolaryngology, Culiacan General Hospital, Culiacán, \\ Sinaloa, México \\ ${ }^{3}$ Department of Otolaryngology, General Hospital Regional No. 1 \\ "Ignacio García Téllez" del IMSS, Mérida, Yucatán, México \\ ${ }^{4}$ Department of Pathology, Centro de Investigación y Docencia en \\ Ciencias de la Salud (CIDOCS), Universidad Autónoma de Sinaloa, \\ Culiacán, Sinaloa, México \\ Int Arch Otorhinolaryngol 2019;23:92-100. \\ Address for correspondence Erika Celis-Aguilar, MD, Blvd. Alfonso G. \\ Calderón No.2193 Poniente, Cons. 603. Desarrollo Urbano Tres Ríos. \\ Zip code 80050. Culiacán, Sinaloa, México \\ (e-mail: erikacelis@hotmail.com).
}

\begin{abstract}
\section{Keywords}

- mucormycosis

- mucorales

- paranasal sinuses

- sinusitis

- mycoses

- chronic mucormycosis

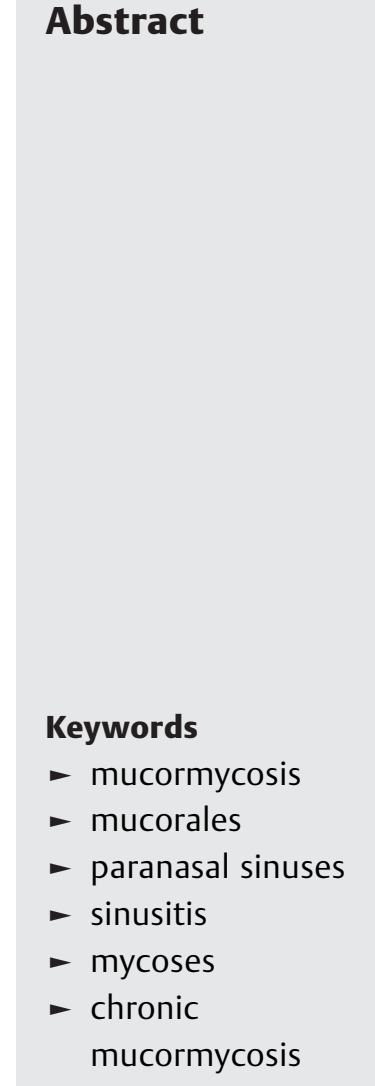

Introduction Indolent or chronic mucormycosis is a rare entity that affects both immunosuppressed and immunocompetent individuals. Additionally, its clinical evolution is nonspecific and there is no standardized treatment for this condition.

Objective To describe the clinical characteristics and management of patients with indolent mucormycosis.

Methods In the project of study with chart review in the Interinstitutional secondary care centers, patients with evidence of indolent mucormycosis, defined as pathological confirmation of nasal/paranasal sinus mucormycosis for more than 1 month, were included. All patients underwent complete laboratory workup, imaging studies, surgical treatment and adequate follow-up. No evidence of disease status was defined when patient had subsequent biopsies with no evidence of mucormycosis.

Results We included seven patients, three female and four male subjects. The mean age was 53.14 years. Four patients were immunosuppressed and three immunocompetent. Among the immunosuppressed patients three had diabetes and one had dermatomyositis. The symptoms were nonspecific: facial pain/headache, mucoid discharge and cacosmia were the ones most frequently reported. Maxillary sinus involvement was present in all patients. Two immunosuppressed subjects received amphotericin. Posaconazole was the only treatment in one immunosuppressed patient. All immunocompetent patients had single paranasal sinus disease and received only surgical treatment. All patients are alive and free of disease. Conclusion Indolent mucormycosis is a new and emerging clinical entity in immunosuppressed and immunocompetent patients. Single paranasal sinus disease is a frequent presentation and should not be overlooked as a differential diagnosis in these patients. Immunocompetent patients should only be treated surgically.
\end{abstract}

received

October 29, 2017

accepted

May 23, 2018

published online

October 24, 2018
DOI https://doi.org/

10.1055/s-0038-1667005. ISSN $1809-9777$.
Copyright (e 2019 by Thieme Revinter

Publicações Ltda, Rio de Janeiro, Brazil
License terms

(요 $\Theta \circledast$ 


\section{Introduction}

Mucormycosis is commonly a fatal infection caused by fungi of the order Mucorales, with Rhizopus being the most common species associated with this disease. ${ }^{1}$ Other isolated species are Absidia, Mucor and Rhizomucor. ${ }^{2,3}$ Histologically, it presents with hyphae that are broad-based and non septated with right angles. ${ }^{4,5}$ Since this is predominantly a fulminant disease, it is potentially lethal. ${ }^{5}$ Patients are usually immunosuppressed individuals, and the clinical hallmark has been vascular invasion with tissue necrosis. ${ }^{6}$ Nonetheless, new cases of indolent mucormycosis are being reported, occurring among immunosuppressed ${ }^{4,7-9}$ and immunocompetent patients. ${ }^{10-15}$ The clinical characteristics are distinguished by its chronic evolution, ${ }^{14}$ nonspecific symptoms and in some cases absence of frank vascular invasion and necrosis. ${ }^{5}$ Additionally, single paranasal sinus disease is also a frequent presentation. ${ }^{11}$ We currently address this new form of disease with recent evidence. The objective of this study is to describe the clinical characteristics and management of patients with indolent mucormycosis.

\section{Methods}

\section{Patients}

The patients were recruited from November 2012 to November 2016. This study was a multicenter clinical chart review conducted in secondary care centers. Indolent mucormycosis was defined as pathological evidence of nasal/paranasal sinus mucormycosis for longer than 1 month. The inclusion criteria were patients with indolent mucormycosis who had pathological confirmation, complete imaging studies and underwent surgical/medical treatment with adequate follow-up.

This is an interinstitutional study approved by the ethical committees of the hospitals involved and led by Centro de Investigación y Docencia en Ciencias de la Salud (CIDOCS) de la Universidad Autónoma de Sinaloa, Sinaloa, Mexico. A signed informed consent was obtained from all patients.

\section{Evaluation and Surgical Technique}

All patients were evaluated by the otolaryngology and the infectiology departments. All patients underwent imaging, laboratory workup and surgical treatment. The patients were operated on by certified interinstitutional otolaryngologists.

The surgical procedures consisted in external maxillary approach (modified Caldwell-Luc procedure), endoscopic ethmoidectomy and antrostomy. The endoscopic procedure consisted in the removal of the uncinated process, ethmoid bulla; the resection of anterior and posterior ethmoid cells was done depending on the extension of disease. The identification of the natural maxillary ostium was performed and enlarged with a backbite and a $45^{\circ}$ Blakesley forceps.

All surgical specimens were evaluated by two certified pathologists.

\section{Statistical Analysis}

The data were gathered by clinical chart review. The statistical analysis was performed using the Statistical Package for the Social Sciences (SPSS) 18.0 (SPSS Inc., Chicago, IL, USA).
The statistical analysis included descriptive statistics (mean and standard deviation).

\section{Results}

\section{Demographic Data}

We included seven patients, three female and four male subjects. The mean age was 53.14 years. Four patients were immunosuppressed and three were immunocompetent. Maxillary sinus involvement was present in all patients.

Among the immunosuppressed patients, three had diabetes and one had dermatomyositis. The symptoms were nonspecific. Facial pain, mucoid discharge and cacosmia were the symptoms most frequently reported. (See - Table $\mathbf{1}$ ).

The duration of symptoms ranged from 1 to 28 months. Two patients had asymptomatic mucormycosis, found incidentally on computed tomography (CT) scan (cases 3 and 5).

\section{Immunosuppressed Cases}

Case 1 was a 38-year-old female patient who presented initially with fulminant mucormycosis disease. Middle turbinate resection, modified Caldwell-Luc procedure and endoscopic ethmoidectomy were urgently performed. Necrosis was seen intraoperatively in the middle turbinate. In spite of ocular involvement (proptosis, pupillary dilation and restriction of ocular movements), we decided on ocular preservation and hospitalization for a period of 1 month, with strict metabolic control, and administration of up to $3 \mathrm{~g}$ of amphotericin. At the end of the month, she was asymptomatic, and ocular involvement was stable. Nonetheless, the magnetic resonance imaging (MRI) and CT scan showed progressive orbital apex pathology. An intraconal biopsy was performed, with final pathology result of mucormycosis. She underwent orbital exenteration with confirmation of orbital disease. Subsequent biopsies of maxillary and ethmoid sinus were negative. This case was included because it shows a patient with persistent disease that developed chronic symptoms. Once amphotericin was prescribed for 1 month, the patient had no disease progression and no additional symptoms. The disease was confined to the orbital fat. The fulminant course was arrested and led to an indolent one. See - Fig. 1.

Case two was diagnosed with diabetes during her hospitalization. Initial nasal endoscopy revealed only middle meatus edema. Surgical findings were compatible with fungus ball and necrosis of maxillary mucosa. Pathology study of the mucosa revealed mucormycosis. Two subsequent biopsies were performed, and the last biopsy showed no evidence of disease. See - Fig. 2.

Case three was asymptomatic. The patient had diabetes and renal failure and, since he was a candidate for a kidney transplant, a paranasal sinus CT scan was performed. Sinus occupation required mandatory surgery, which later led to the diagnosis of mucormycosis. Subsequent biopsies were negative. - Fig. 3 shows histopathological confirmation.

Case four had dermatomyositis. Patient complained of nasal obstruction, facial fullness, chronic rhinorrhea with posterior discharge and cough. Paranasal sinus CT scan was performed with left maxillary sinus occupation. See - Table 1 for additional symptoms and treatment. See - Fig. 4 for preoperative CT scan. 
Table 1 Demographics and clinical characteristics of the study population

\begin{tabular}{|c|c|c|c|c|c|c|c|c|}
\hline $\begin{array}{l}\text { Patient } \\
\text { number }\end{array}$ & Sex & Age & $\begin{array}{l}\text { Immunocompetent } \\
\text { status }\end{array}$ & $\begin{array}{l}\text { Anatomic } \\
\text { localization }\end{array}$ & $\begin{array}{l}\text { Duration of } \\
\text { symptoms } \\
\text { (mo) }\end{array}$ & Clinical features & Treatment & Follow-up \\
\hline 1 & $\mathrm{~F}$ & 38 & Immunosuppressed & $\begin{array}{l}\text { Rhino-orbital } \\
\text { Left maxillary } \\
\text { Left ethmoid } \\
\text { Left orbit }\end{array}$ & 1 & $\begin{array}{l}\text { Maxillary pain, } \\
\text { proptosis, pupil } \\
\text { dilation, restriction of } \\
\text { ocular movements. } \\
\text { Acute facial pain }\end{array}$ & $\begin{array}{l}\text { Antrostromy, } \\
\text { Cadwell Luc, } \\
\text { ethmoidectomy, } \\
\text { orbital exenteration, } \\
\text { liposomal amphotericine B } \\
\text { with a total accumulative } \\
\text { dose of } 3 \mathrm{~g} \text {, } \\
\text { posaconazole } 45 \text { days }\end{array}$ & $\begin{array}{l}4 \text { years } \\
\text { follow up } \\
\text { NED }\end{array}$ \\
\hline 2 & $\mathrm{~F}$ & 61 & Immunosuppressed & $\begin{array}{l}\text { Left maxillary } \\
\text { sinus }\end{array}$ & 6 & $\begin{array}{l}\text { Headache, facial pain, } \\
\text { purulent rhinorrhea, } \\
\text { halitosis, cacosmia. }\end{array}$ & $\begin{array}{l}\text { Caldwell Luc, } \\
\text { endoscopic antrostomy, } \\
\text { amphotericin B } 750 \mathrm{mg}\end{array}$ & $\begin{array}{l}2.5 \text { years } \\
\text { follow up, } \\
\text { NED }\end{array}$ \\
\hline 3 & M & 54 & Immunosuppressed & $\begin{array}{l}\text { Right maxillary } \\
\text { sinus }\end{array}$ & NA & Asymptomatic & $\begin{array}{l}\text { Caldwell Luc } \\
\text { Posaconazole }\end{array}$ & $\begin{array}{l}2 \text { years } \\
\text { follow up, } \\
\text { NED }\end{array}$ \\
\hline 4 & $\mathrm{~F}$ & 46 & Immunosuppressed & $\begin{array}{l}\text { Left maxillary } \\
\text { sinus }\end{array}$ & 28 & $\begin{array}{l}\text { Nasal obstruction, } \\
\text { facial fullness, chronic } \\
\text { rhinorrhea with } \\
\text { posterior discharge } \\
\text { and cough. }\end{array}$ & Caldwell Luc & 2 months \\
\hline 5 & M & 77 & Immunocompetent & $\begin{array}{l}\text { Left maxillary } \\
\text { sinus }\end{array}$ & NA & $\begin{array}{l}\text { Contralateral nasal } \\
\text { mass } \\
\text { Right Nasal } \\
\text { obstruction, Left side } \\
\text { asymptomatic. }\end{array}$ & $\begin{array}{l}\text { Resection of } \\
\text { contralateral mass } \\
\text { Left Caldwell Luc and } \\
\text { endoscopic antrostomy }\end{array}$ & $\begin{array}{l}1 \text { year } \\
\text { follow up, } \\
\text { NED }\end{array}$ \\
\hline 6 & $M$ & 54 & Immunocompetent & $\begin{array}{l}\text { Right maxillary } \\
\text { sinus }\end{array}$ & 8 & Headache, cacosmia & $\begin{array}{l}\text { Caldwell Luc and endo- } \\
\text { scopic } \\
\text { antrostomy (Caldwell } \\
\text { Luc a year after, } \\
\text { no recurrence) }\end{array}$ & $\begin{array}{l}1.6 \text { years, } \\
\text { asymptomatic, } \\
\text { NED }\end{array}$ \\
\hline 7 & M & 42 & Immunocompetent & $\begin{array}{l}\text { Left maxillary } \\
\text { sinus }\end{array}$ & 24 & $\begin{array}{l}\text { Mucoid discharge, } \\
\text { nasal obstruction, } \\
\text { headache. }\end{array}$ & $\begin{array}{l}\text { Caldwell Luc, } \\
\text { endoscopic antrostomy }\end{array}$ & $\begin{array}{l}1 \text { year } \\
\text { follow up, } \\
\text { NED }\end{array}$ \\
\hline
\end{tabular}

Abbreviations: F, female; M, male; mo, months; NA, none available; NED, no evidence of disease.

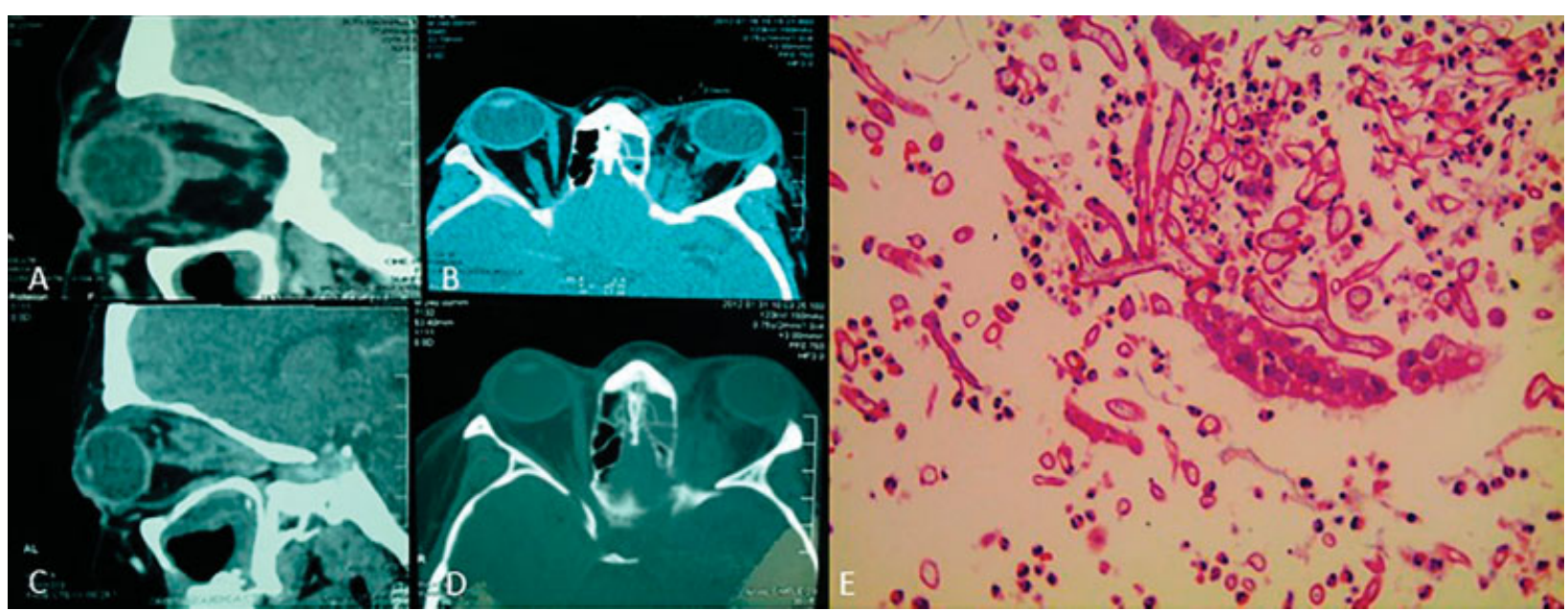

Fig. 1 Case 1. Chronic orbital mucormycosis. (A-D) Computed tomography scan shows intraorbital density, predominantly on the apex region. (E). Periodic acid-Schiff (PAS) stain showing mucormycosis with 90-degrees non-septated hyphae.

\section{Immunocompetent}

Among the immunocompetent cases (5, 6, and 7), one patient had cocaine addiction, interrupted 5 years earlier and 2 patients had previous septoplasties.

Patient number 5 had right nasal polyp as the only cause of nasal symptoms. Mucormycosis was contralateral and asymptomatic. See -Figs. 5, 6 and 7. See -Table 1 for complete description of symptoms and treatments.

\section{Treatment}

All patients underwent surgical treatment, which consisted mainly in an external maxillary approach and endoscopic 


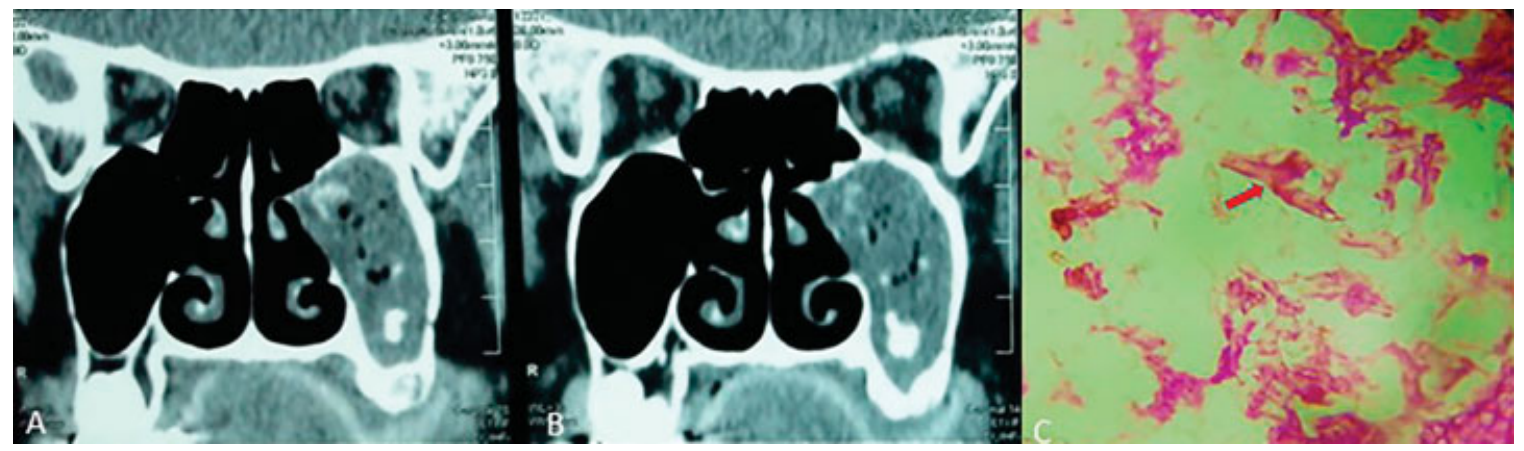

Fig. 2 Case 2. (A and B) Computed tomography scan shows left maxillary sinus with heterogeneous density and osteitis. (C) Hematoxylin eosin stain (100x) and (D) Periodic acid-Schaff stain (400x) demonstrate respiratory epithelium with thick hyphae; at higher magnification, non-septated hyphae with right angles are confirmed (red arrow).

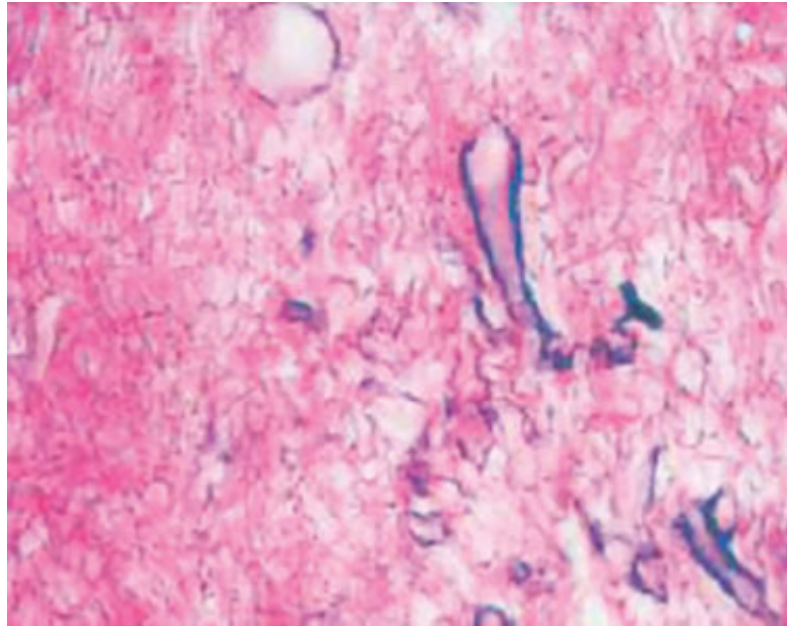

Fig. 3 Case 3. Pathology specimen shows edematous mucosa with lymphocyte and plasmatic cells infiltration. Abundant irregular hyphae were observed, with 15 to $30 \mu \mathrm{m}$, broad with thin wall, non septated, with irregular ramifications filling blood vessels.

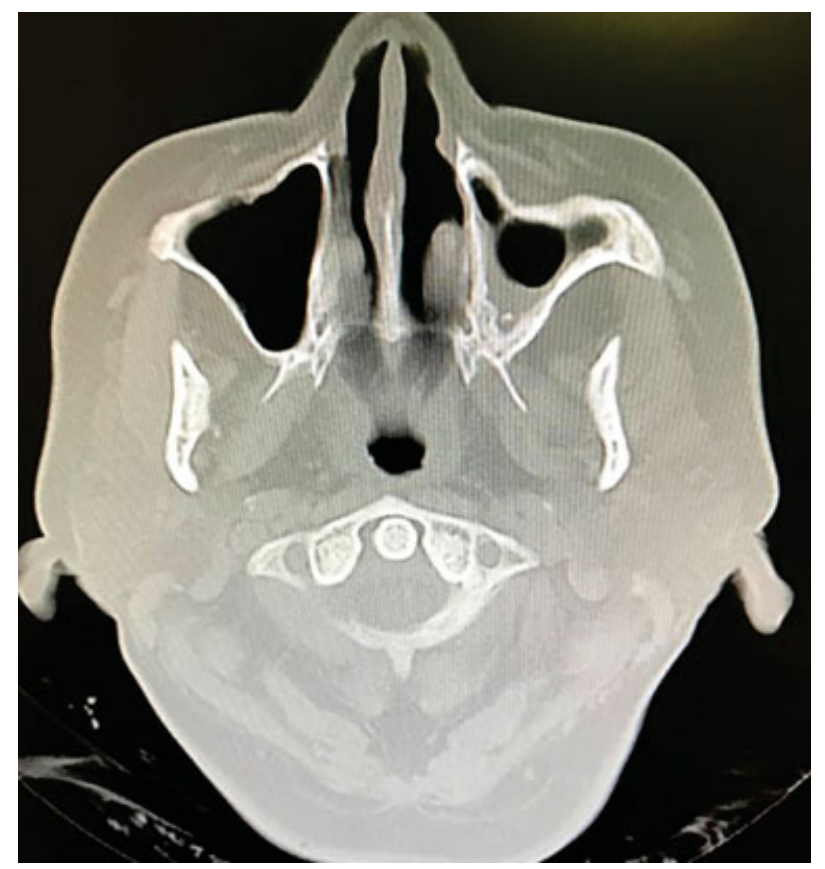

Fig. 4 Case 4. Computed tomography scan showing osteitis of maxillary walls and occupation with heterogeneous density of left maxillary sinus. antrostomy. Regarding medical treatment, one immunosuppressed subject received only amphotericin, and case one received both amphotericin and posaconazole. On the other hand, posaconazole was the only treatment in one immunosuppressed patient. (See - Table 1)

All immunocompetent patients had unilateral maxillary sinus involvement and received only surgical treatment, with resolution of the disease. The surgical findings in these patients were similar: black and abundant debris in the maxillary sinus. Two immunocompetent patients had signs of necrosis in the maxillary mucosa. Interestingly, only case one had evident necrosis at nasal endoscopy.

\section{Discussion}

Mucormycosis refers to any fungal infection by members of the order mucorales, which is in the class zygomycetes. Most pathogenic species are members of the family mucoraceae. ${ }^{1,8}$ It is currently known that mucormycosis affects mainly immunosuppressed individuals, ${ }^{16}$ especially uncontrolled diabetic patients with acidosis. Deferoxamine therapy and trauma have also been described as risk factors. ${ }^{1,8,13,17}$ Furthermore, immunocompetent individuals are also prone to this disease. ${ }^{18}$ Unfortunately, the previous literature has mainly described the fulminant course of this disease.

Chronic or indolent mucormycosis of the paranasal sinuses was described initially in $1964 .{ }^{19}$ Although the disease is not universally known, over 30 cases have been described in the literature. ${ }^{15,20}$ Interestingly, indolent mucormycosis can affect immunocompetent and immunosuppressed individuals. Although, immunocompetent cases are associated with a less severe disease. ${ }^{7}$

On the other hand, chronic invasive fungal sinusitis has generally been associated with the aspergillus species, ${ }^{10}$ reinforcing the concept that mucormycosis develops only into an acute fulminant course. It is the objective of this paper to describe the chronic presentation of mucormycosis and to show our experience in the treatment of both immunocompetent and immunosuppressed patients.

The definition of chronic mucormycosis has been controversial, since some authors acknowledge a period of only weeks, ${ }^{9,21,22}$ while others consider it necessary the presence of mucormycosis for at least 1 month. ${ }^{4}$ All the patients 


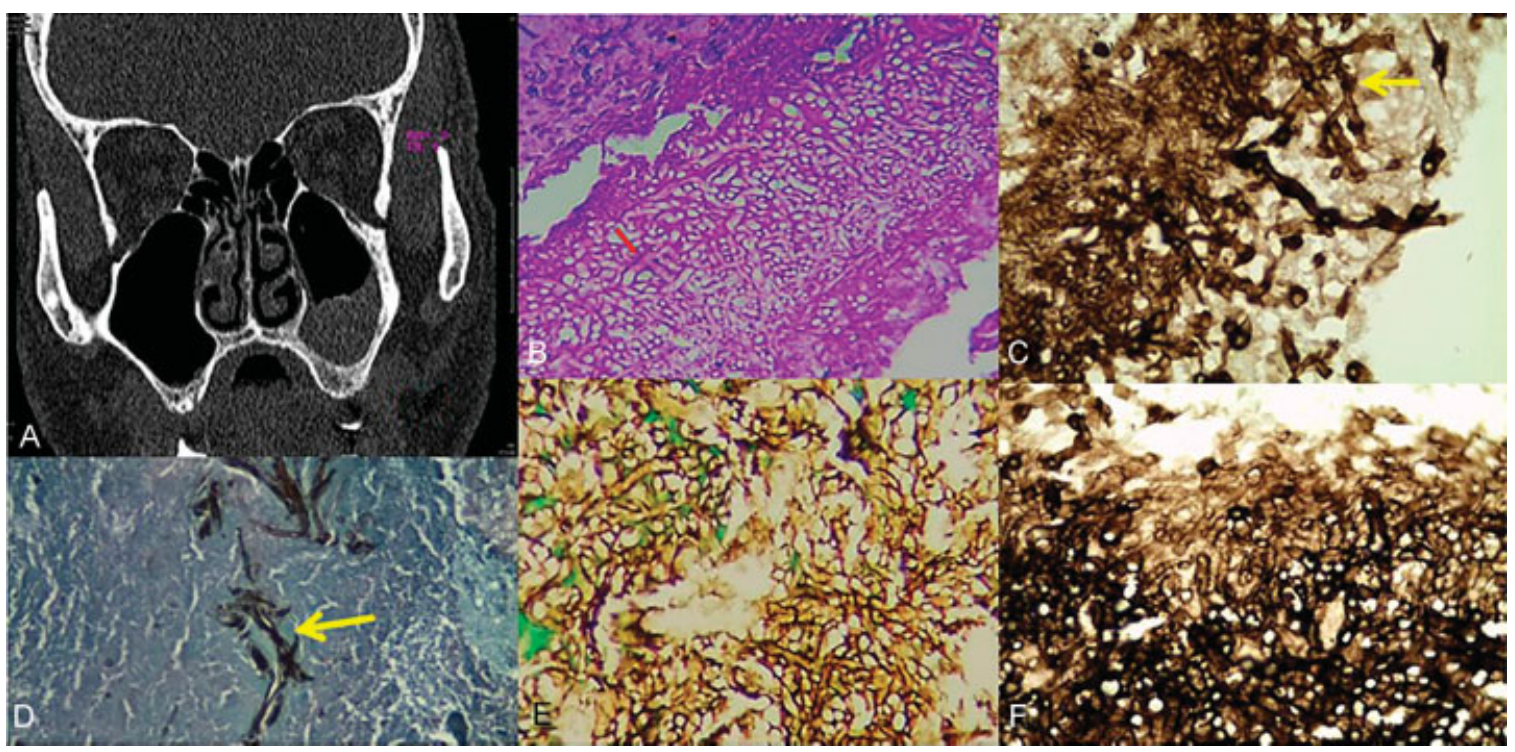

Fig. 5 Case 5. (A) Computed tomography scan demonstrates left maxillary sinus occupation. (B) Periodic acid-Schaff stain (100x): necrotic tissue with mixed inflammatory cells and hyphae with diverse diameters non septated, with some showing 90-degrees angulation, compatible with mucor (red arrow). (C, D, E, F) Grocott Gomori stain (40x, 100x, 400x): abundant non-septated hyphae with 90-degree angulation; this stain was highly positive on hyphae walls.

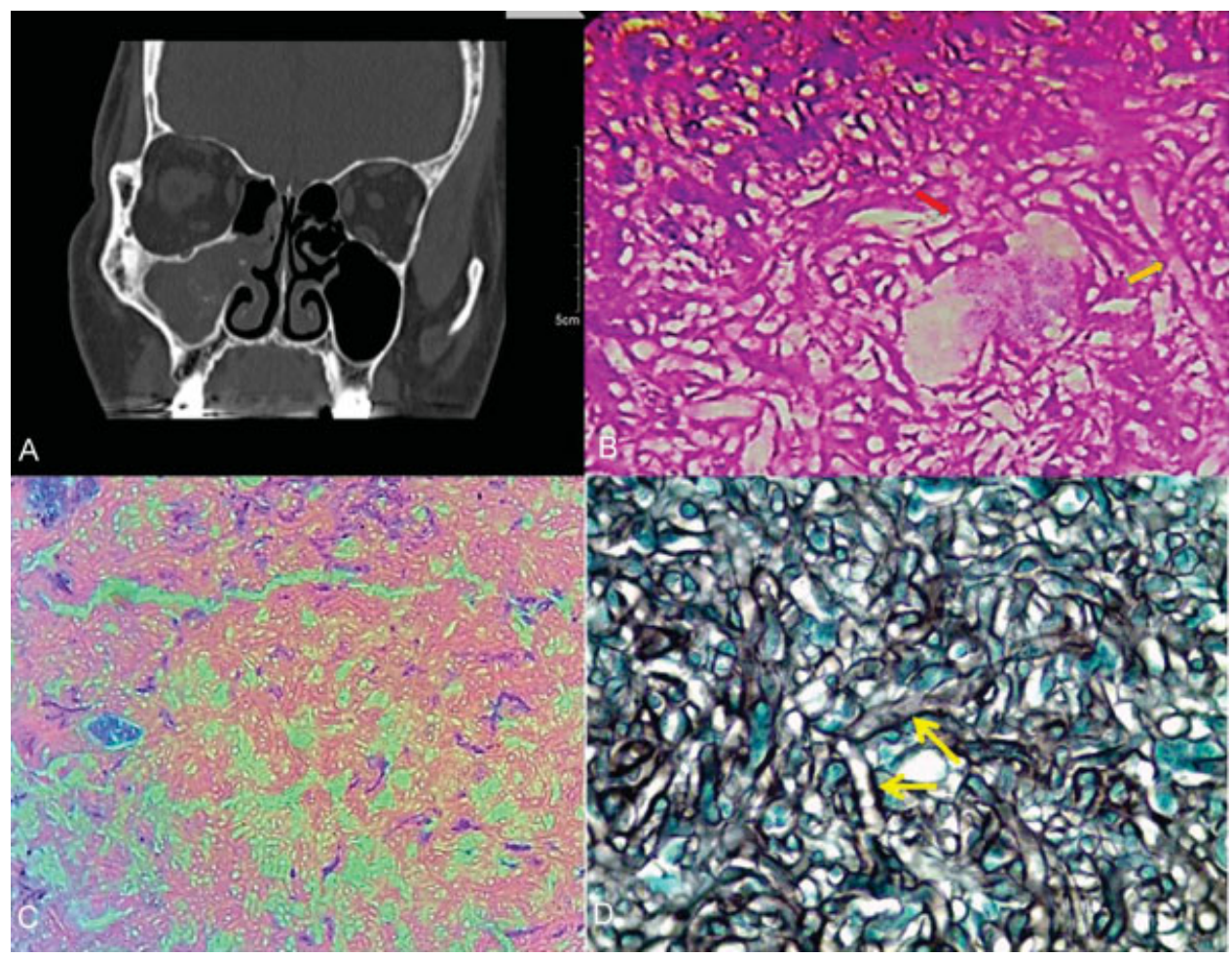

Fig. 6 Case 6. (A) Computed tomography scan with total right maxillary sinus heterogeneous occupation. (B) Periodic acid-Schiff stain (400x) shows numerous thick hyphae semi-septated (yellow arrow) with 90-degrees angulation (red arrow) (C) Hematoxylin eosin stain (100x) shows abundant pauci-septated hyphae with right angles and necrosis. (D) Grocott Gomori stain (100X) shows abundant hyphae compatible with zygomycetes.

included in our study had at least 1 month of suggestive mucormycosis infection.

Also, chronic mucormycosis has been associated with internal carotid artery occlusion, ${ }^{9}$ although none of our patients developed this complication. One common clinical feature we could find in most of our patients was the presence of facial pain or headache. This could be a hallmark symptom when faced with a patient with chronic paranasal sinus disease with evident CT scan sinus occupation. Some authors $^{5,23,24}$ also describe this pain frequently in their 


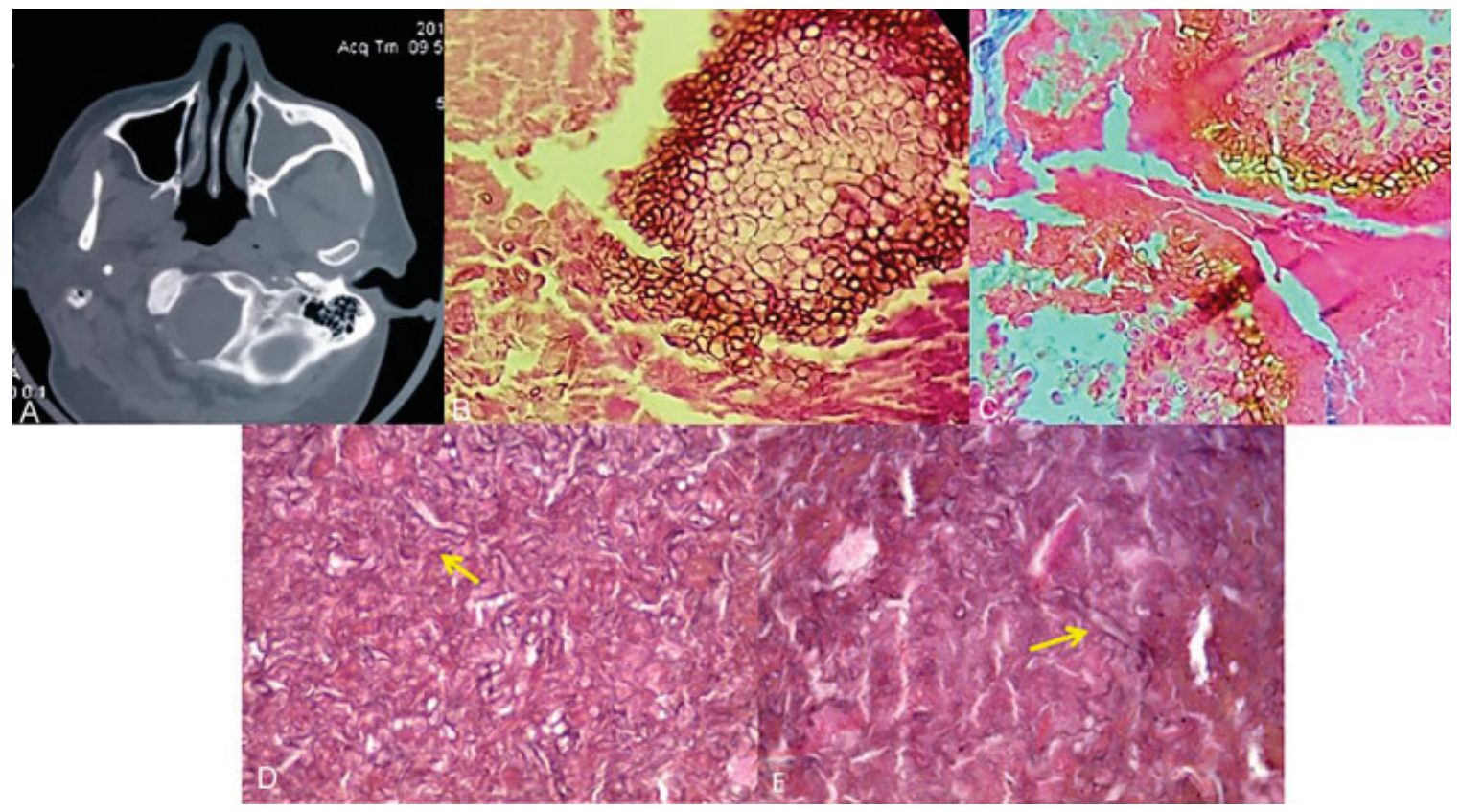

Fig. 7 Case 7. (A) Computed tomography scan with left total maxillary sinus occupation. (B) Periodic acid-Schiff (PAS) stain (400x) showing spores and scant hyphae compatible with mucormycosis. (C) Hematoxylin eosin stain $(400 \mathrm{x})$ showing inflammatory cells, spores and hyphae compatible with mucor. Figure D and E show non-septated hyphae on PAS stain (100x).

patients. ${ }^{6}$ In our study, only one patient had orbital apex syndrome. This patient had middle turbinate necrosis, evident at nasal endoscopy. Necrosis was seen in most of our patients during modified Caldwell-Luc procedure in maxillary mucosa, but no evidence of necrosis was seen on rhinoscopy or nasal endoscopy. This defies the current knowledge that necrosis is usually seen at the physical exploration of these patients. In our study, maxillary sinus disease was the most common paranasal sinus involved, pointing to a more limited disease. Curiously, other authors have described a more aggressive course with orbital apex syndrome, cavernous sinus thrombosis ${ }^{4,21,22}$ and brain abscess. ${ }^{25}$ Although, on immunocompetent patients, the disease has been more localized. ${ }^{5,10,26}$ Other authors have corroborated single paranasal sinus disease on immunocompetent patients. ${ }^{71,12,15,16}$ See - Table $\mathbf{2}$ and $\mathbf{3}$ for a brief review of the literature.

The CT scan in some of these cases may not have the typical erosion of sinus wall. Mignogna et al and Ketenci et al did not find erosion in the CT scans of their patients, only sinus occupation. Erosion could not be considered a hallmark sign in chronic mucormycosis cases.

Among the immunosuppressed patients, case one began with a fulminant mucormycosis disease, only to progress to an indolent orbital course. During the patient's hospitalization, efforts for orbital preservation led to continued observation in an otherwise stable patient; nonetheless, orbital apex disease progression was seen on subsequent $\mathrm{CT}$ scans, with additional mucormycosis pathological confirmation ultimately leading to orbital exenteration. It is possible that treatment with amphotericin B lead in fact to an indolent course in case number 1. only amphotericine treatment on iniatilly invasive mucormycosis cases with no surgery could lead to an indolent course.
Careful imaging follow-up is necessary, especially in cases of orbital disease. Also, a chronic orbital case treated with a course of antifungals could erroneously lead a surgeon to do no further surgery, which, in fact, happened in this case, making it necessary first, an orbital biopsy and later, with this being positive, an exenteration. Mutilation of a patient (exenteration) is a difficult decision. This article recommends immediate orbital exenteration in case of progressive orbital disease, only evident on CT scan.

Since this is an infrequent disease, no randomized control trials are possible, and only case series are reported in the literature. $^{15}$ Therefore, there is controversy on the best treatment available for this pathology. Some authors advocate a surgical and amphotericin B treatment, ${ }^{4,7,27,28}$ while others support only the surgical or medical treatment, such as monotherapy. ${ }^{11,12}$ These patients, as many authors point out, have different comorbidities that contraindicate either the use of amphotericin or surgical treatment. Several case reports showed us that monotherapy is a viable treatment with good results. ${ }^{19,22}$ Additionally, many authors describe a persistent disease with a very slow progression that has no impact on the quality of life of the patient. $5,10,27,28$

We agree with Tyson et $\mathrm{al}^{5}{ }^{5}$ Seung et $\mathrm{al}^{7}$ Jung $\mathrm{H}$, et $\mathrm{al}^{11}$ and Ketenci et $\mathrm{al}^{27}$ that an only surgical treatment in immunocompetent patients is possible. Interestingly, there has been a rise in the reported cases of acute and chronic mucormycosis. $^{1,2}$ This could mean an increased interest in publishing these cases, more awareness of this disease with prompt diagnosis and treatment, or a real increment of mucormycosis cases due to more diabetic or immunosuppressed patients. A possible explanation to indolent mucormycosis in Mexico is the tropical weather and high temperature of this geographical area, which could increase the risk of fungal infection. Other 


\begin{tabular}{|c|c|c|c|c|c|c|c|c|c|c|c|c|c|c|c|}
\hline & 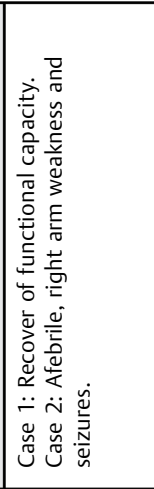 & 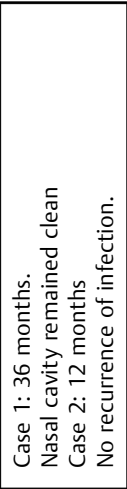 & 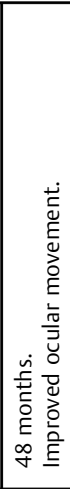 & 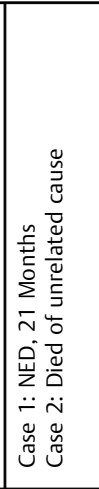 & 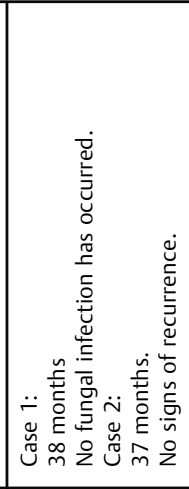 & 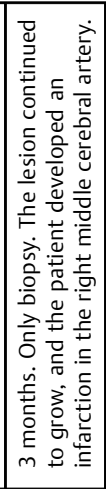 & 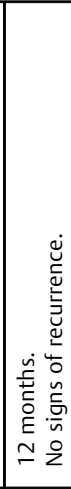 & 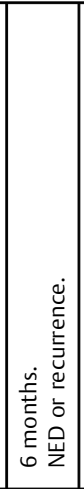 & 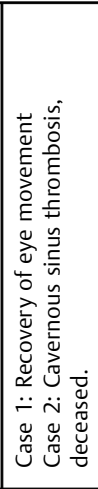 & 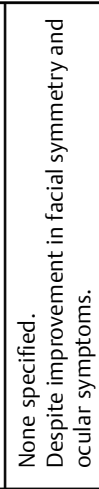 & 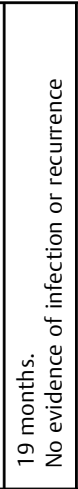 & 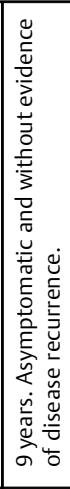 & 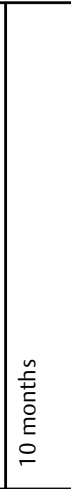 & 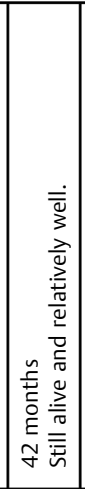 & 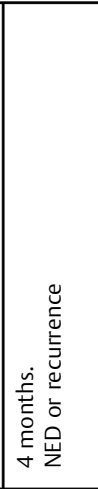 \\
\hline & $>>$ & $>z$ & $>$ & $>>$ & $>>$ & $>$ & $>$ & $>$ & $z>$ & $>$ & $>$ & $>$ & z & $>$ & $>$ \\
\hline & $>z$ & $z z$ & $z$ & $z z$ & $z z$ & z & $>$ & $z$ & $z>$ & $z$ & $z$ & $>$ & z & $z$ & z \\
\hline & $>>$ & $>>$ & $>$ & $>>$ & $>>$ & $z$ & $>$ & $z$ & $>>$ & $>$ & $>$ & $>$ & $>$ & $z$ & $>$ \\
\hline & 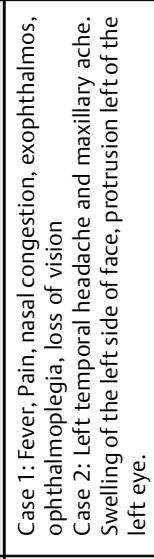 & 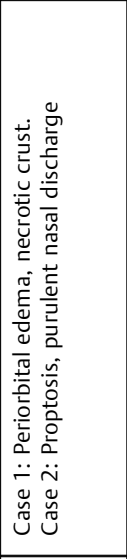 & 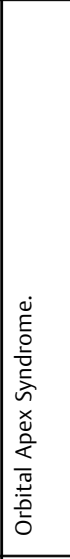 & 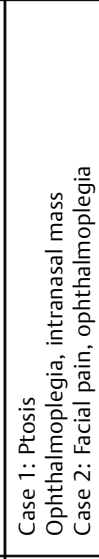 & 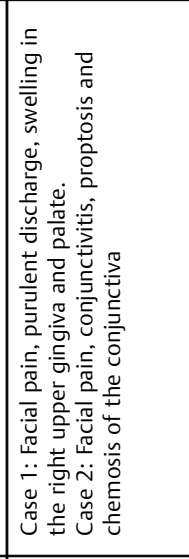 & 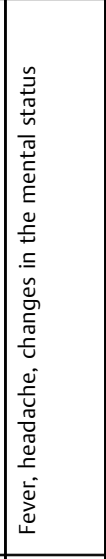 & 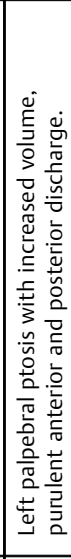 & 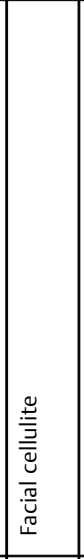 & 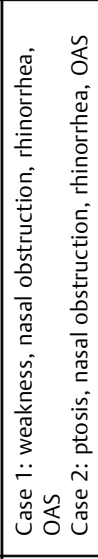 & 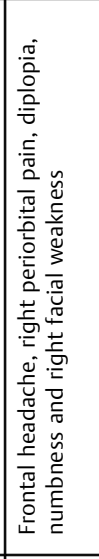 & 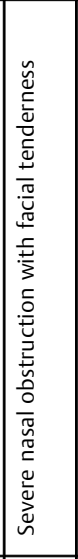 & 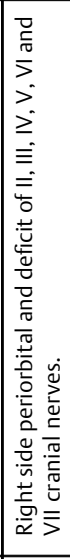 & 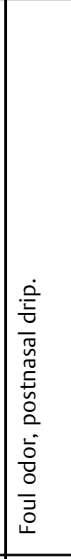 & 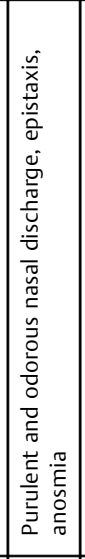 & 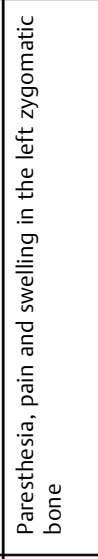 \\
\hline & $-\stackrel{\text { ng }}{\circ}$ & & $\stackrel{\text { In }}{\longrightarrow}$ & 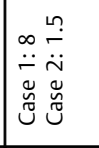 & 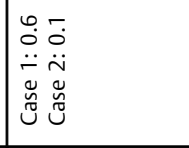 & m & $m$ & & - & 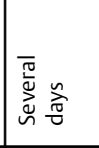 & 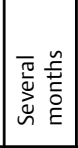 & $\stackrel{n}{4}$ & $\stackrel{m}{m}$ & 0 & m \\
\hline & $>z$ & $z z$ & z & $z z$ & $z z$ & $\underline{\cup}$ & $z$ & $z$ & $z z$ & z & $z$ & $z$ & $z$ & $z$ & $z$ \\
\hline & $z z$ & $z z$ & $>$ & $>>$ & $z z$ & z & $>$ & z & $>z$ & z & $z$ & $>$ & z & z & $z$ \\
\hline & $z z$ & $>z$ & $>$ & $>>$ & $z>$ & $>$ & $>$ & z & $>>$ & $z$ & $z$ & z & $z$ & $>$ & $z$ \\
\hline & $>>$ & $>z$ & $>$ & $>z$ & $z>$ & z & $>$ & $>$ & $>>$ & $z$ & $z$ & $>$ & $z$ & $>$ & z \\
\hline & $>>$ & $z>$ & z & $>z$ & $>>$ & z & $>$ & $>$ & $>>$ & $>$ & $>$ & z & $>$ & $>$ & $>$ \\
\hline & $\sum_{0} \sum_{0}$ & 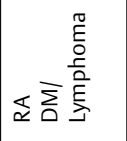 & $\Sigma$ & ¿̇z & 飬 & 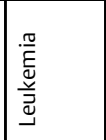 & 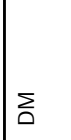 & 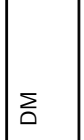 & ¿̇ & $\sum_{0} \stackrel{\alpha}{<}$ & I & $\underline{\Sigma}$ & $\Sigma$ & $\sum$ & 玄 \\
\hline & $5 \stackrel{\circ}{\circ}$ & న $\infty_{\llcorner}^{\infty}$ & ๖ & \& : & $G \pi$ & $\stackrel{0}{\circ}$ & 员 & $\overline{6}$ & SN & t & in & f & 6 & 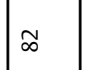 & f \\
\hline & $4 \Sigma$ & $4 \Sigma$ & $\Sigma$ & $\llcorner\sqcup$ & $4 \Sigma$ & $\Sigma$ & $\Sigma$ & $E$ & $\Sigma \Sigma$ & $\Sigma$ & \llcorner & 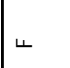 & 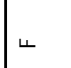 & $\Sigma$ & $\Sigma$ \\
\hline & $\sim$ & $\sim$ & - & $\sim$ & $\sim$ & - & - & - & $\sim$ & - & - & - & - & - & - \\
\hline & 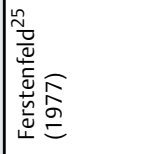 & 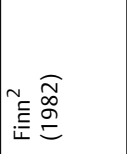 & 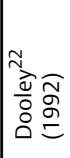 & 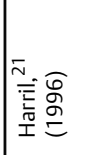 & 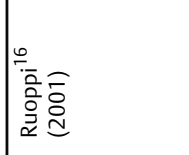 & 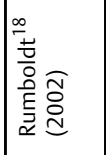 & 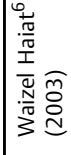 & 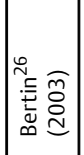 & 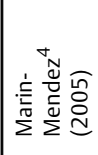 & 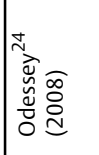 & $=\frac{\widehat{m}}{\tilde{\underline{\sigma}}}$ & 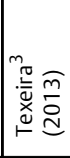 & 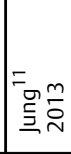 & 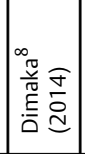 & 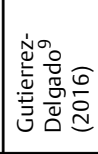 \\
\hline
\end{tabular}




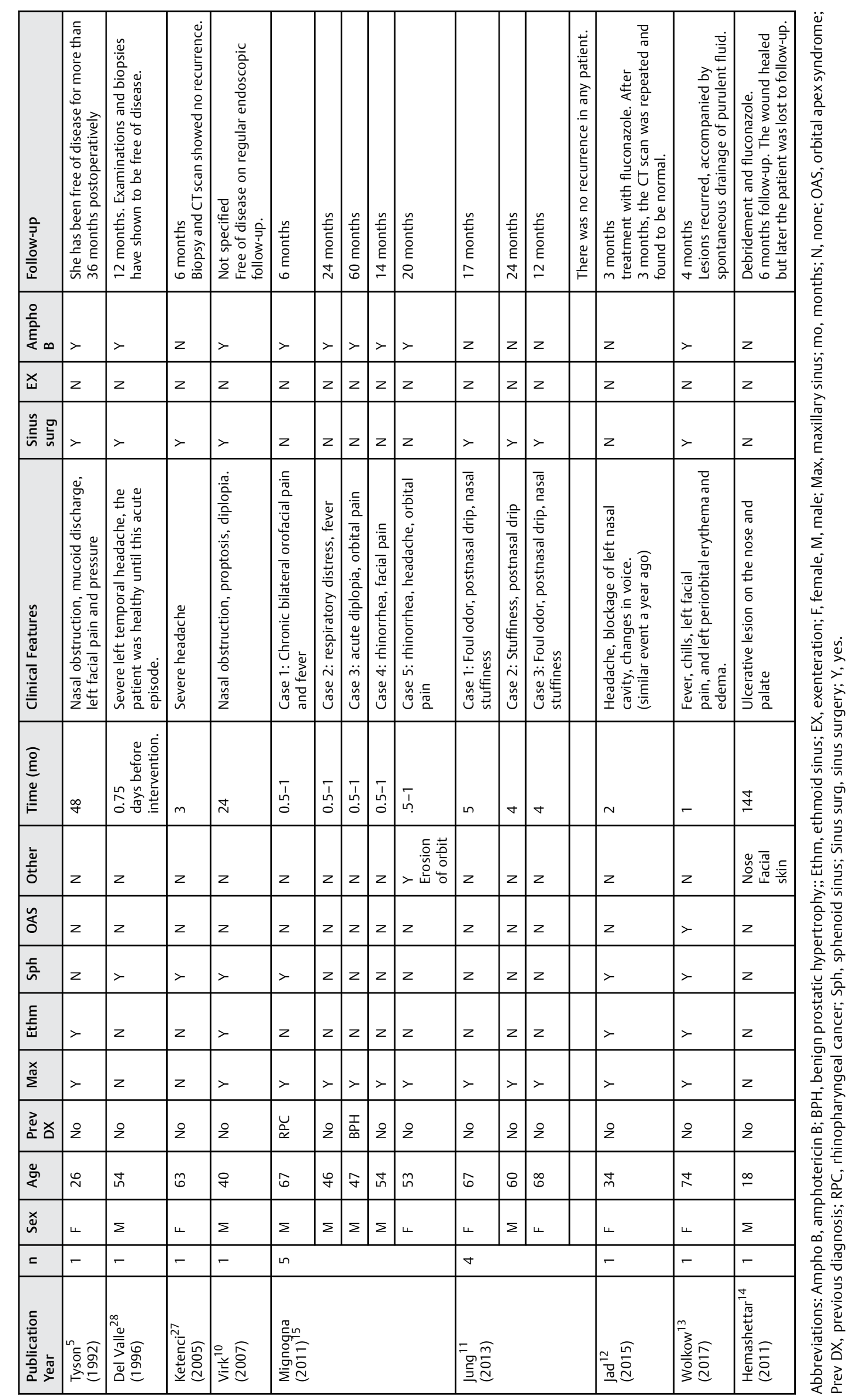


authors have hypothesized that chronic sinusitis could be a risk factor for this fungal infection. ${ }^{15}$

In contrast to acute fulminant invasive sinusitis, chronic mucormycosis could have better survival. In a recent systematic review, ${ }^{20}$ only half of the patients with acute fulminant disease survived, with diabetic patients having better prognosis than patients with other comorbidities. Chronic mucormycosis, at least in our series, had a $100 \%$ survival rate. Other authors support this improvement in survival, especially in immunocompetent patients. $5,10,11,24,27$

Differential diagnosis of this disease should be kept in mind, such as neoplasms, bacterial sinusitis, granulomatous disorders, cavernous sinus thrombosis, pseudotumors, etc. ${ }^{9}$

The limitations of this study are mainly the lack of mucormycosis cultures. Nonetheless, the characteristic broad non-septated hyphae with right angle branching usually suffices for diagnosis. Since this is an emerging entity, we are confident that new studies could confirm our results and shed new light on this disease.

The strengths of this study are the high number of patients included, in contrast to what has been previously published, the longer follow-up and the fact that it is a multicenter study.

Finally, indolent mucormycosis is a differential diagnosis in patients with facial pain or headache, mucoid discharge, cacosmia with a paranasal sinus occupation on CT scan in immunosuppressed and immunocompetent individuals.

\section{Conclusion}

Indolent mucormycosis is a new and emerging clinical entity in immunosuppressed and immunocompetent patients. Single paranasal sinus disease is a frequent presentation and should not be overlooked as a differential diagnosis in these patients. Immunocompetent patients should only be treated surgically. More studies are needed to confirm our results.

\section{References}

1 Ibrahim AS, Kontoyiannis DP. Update on mucormycosis pathogenesis. Curr Opin Infect Dis 2013;26(06):508-515

2 Finn DG, Farmer JC Jr. Chronic mucormycosis. Laryngoscope 1982; 92(7 Pt 1):761-766

3 Teixeira CA, Medeiros PB, Leushner P, Almeida F . Rhinocerebral mucormycosis: literature review apropos of a rare entity. BJM Case Rep 2013. Doi: 10.1136/bcr-2013-008552https://www.ncbi. nlm.nih.gov/pubmed/23389725

4 Marin-Mendez H. Monroy- Aguirre D, Rodríguez- Perales M. Caretta-Barradas Sergio. Síndrome de ápex orbitario causado por mucormicosis orbito cerebral crónica e indolente: reporte de dos casos. An Orl Mex 2005;50:64-68

5 Tyson JC, Gittelman PD, Jacobs JB, Holliday R, Press R. Recurrent mucormycosis of the paranasal sinuses in an immunologically competent host. Otolaryngol Head Neck Surg 1992;107(01):115-119

6 Waizel-Haiat S, Cohn-Zurita F, Vargas-Aguayo AM, RamírezAceves R, Vivar-Acevedo E. Mucormicosis rinocerebral invasora crónica. Cir Cir 2003;71(02):145-149

7 Kim ST, Kim WS, Lee HH, Kim JY. Successful treatment of invasive rhinopulmonary mucormycosis with an indolent presentation by combined medical and surgical therapy. J Craniofac Surg 2013;24 (02):e182-e184

8 Dimaka K, Mallis A, Naxakis SS, et al. Chronic rhinocerebral mucormycosis: a rare case report and review of the literature. Mycoses 2014;57(11):699-702

9 Gutiérrez-Delgado EM, Treviño-González JL, Montemayor-Alatorre A, et al. Chronic rhino-orbito-cerebral mucormycosis: A case report and review of the literature. Ann Med Surg (Lond) 2016;6:87-91

10 Virk RS, Arora P. Chronic sinonasal aspergillosis with associated mucormycosis. Ear Nose Throat J 2007;86(01):22

11 Jung H, Park SK. Indolent mucormycosis of the paranasal sinus in immunocompetent patients: are antifungal drugs needed? J Laryngol Otol 2013;127(09):872-875

12 Jad B, Pottathil S, Raina S, Singh V. Paranasal Sinus Mucormycosis in an Immunocompetent Host: A Case Report. Int J Health Sci Res 2015;5:617-620

13 Wolkow N, Jakobiec FA, Stagner AM, et al. Chronic orbital and calvarial fungal infection with Apophysomyces variabilis in an immunocompetent patient. Surv Ophthalmol 2017;62(01):70-82

14 Hemashettar BM, Patil RN, O’Donnell K, Chaturvedi V, Ren P, Padhye AA. Chronic rhinofacial mucormycosis caused by Mucor irregularis (Rhizomucor variabilis) in India. J Clin Microbiol 2011; 49(06):2372-2375

15 Mignogna MD, Fortuna G, Leuci S, et al. Mucormycosis in immunocompetent patients: a case-series of patients with maxillary sinus involvement and a critical review of the literature. Int J Infect Dis 2011;15(08):e533-e540

16 Ruoppi P, Dietz A, Nikanne E, Seppa J, Markkanen H, Nuutinen J. Paranasal sinus mucormycosis: a report of two cases. Acta Otolaryngol 2001;121(08):948-952

17 Sun HY, Singh N. Mucormycosis: its contemporary face and management strategies. Lancet Infect Dis 2011;11(04):301-311

18 Rumboldt Z, Castillo M. Indolent intracranial mucormycosis: case report. AJNR Am J Neuroradiol 2002;23(06):932-934

19 Vignale R, Mackinnon JE, Casella de Vilaboa E, Burgoa F. Chronic, destructive, mucocutaneous phycomycosis in man. Sabouraudia 1964;3(02):143-147

20 Turner JH, Soudry E, Nayak JV, Hwang PH. Survival outcomes in acute invasive fungal sinusitis: a systematic review and quantitative synthesis of published evidence. Laryngoscope 2013;123 (05):1112-1118

21 Harril WC, Stewart MG, Lee AG, Cernoch P. Chronic rhinocerebral mucormycosis. Laryngoscope 1996;106(10):1292-1297

22 Dooley DP, Hollsten DA, Grimes SR, Moss J Jr. Indolent orbital apex syndrome caused by occult mucormycosis. J Clin Neuroophthalmol 1992;12(04):245-249

23 Rao SP, Kumar KR, Rokade VR, Khanna V, Pal C. Orbital Apex Syndrome due to mucormycosis caused by Rhizopus microsporum. Indian J Otolaryngol Head Neck Surg 2006;58(01):84-87

24 Odessey E, Cohn A, Beaman K, Schechter L. Invasive mucormycosis of the maxillary sinus: extensive destruction with an indolent presentation. Surg Infect (Larchmt) 2008;9(01):91-98

25 Ferstenfeld JE, Cohen SH, Rose HD, Rytel MW. Chronic rhinocerebral phycomycosis in association with diabetes. Postgrad Med J 1977;53(620):337-342

26 Bertin H. Mucormicosis rinosinusal. Rev Otorrinolaringol Cir Cabeza Cuello 2003;63:122-126

27 Ketenci I, Unlü Y, Sentürk M, Tuncer E. Indolent mucormycosis of the sphenoid sinus. Otolaryngol Head Neck Surg 2005;132(02): 341-342

28 Del Valle Zapico A, Rubio Suárez A, Mellado Encinas P, Morales Angulo C, Cabrera Pozuelo E. Mucormycosis of the sphenoid sinus in an otherwise healthy patient. Case report and literature review. J Laryngol Otol 1996;110(05):471-473 